\title{
¿Con Dios y con el Diablo? Reforma social y estrategia política en el reparto de armas de Ciropedia
}

\section{Can't You Run with the Hare and Hunt with the Hounds? Social Reform and Political Strategy in Cyropaedia's Distribution of Weapons}

\author{
Rodrigo Illarraga ${ }^{1}$ \\ Universidad de Buenos Aires - CONICET (Argentina)
}

Recibido: 06-05-17

Aprobado: $30-05-17$

\section{Resumen}

El presente trabajo busca analizar las estrategias políticas utilizadas por Ciro para lograr sus objetivos en el reparto de armas al pueblo en la Ciropedia de Jenofonte. Este episodio es una instancia clave en el proyecto del príncipe persa: Ciro se propone armar a los auxiliares, equiparando su situación militar a la de los homótimoi. En este movimiento abrirá para el pueblo llano el acceso a premios y cargos, lo que representará una intensa reforma político-social. A partir de un estudio detallado de las secciones mencionadas, mostraremos qué concepción de justicia opera detrás del proyecto de Ciro, cómo logra los fines propuestos, y qué imagen de gobernante encarna el príncipe persa.

Palabras-clave: Jenofonte, Ciropedia, política, reformas sociales, socráticos.

\footnotetext{
${ }^{1}$ (rodrigoillarraga@gmail.com). Docente de la Facultad de Filosofía y Letras de la Universidad de Buenos Aires y becario del Consejo Nacional de Investigaciones Científicas y Técnicas (CONICET) sus últimas publicaciones son la traducción (junto a C. Mársico y P. Marzocca) de la Constitución de los lacedemonios, Hierón, y la Constitución de los atenienses (Jenofonte y Pseudo-Jenofonte), Prometeo/Universidad de Quilmes, Buenos Aires, 2017. "El extraño reino de un jóven príncipe. Política, educación y justicia en la sociedad persa de la Ciropedia (1.2.2-16)", Quaderni Urbinati di Cultura Classica (Fabrizio Serra Editore, Italia), 2017 y "Enkráteia y gobierno. El gobernante insensato de Aristipo y su aparición en Ciropedia”, Méthexis 30 (Brill, Paises Bajos), 2018.
} 


\begin{abstract}
This article seeks to analyze the political strategies used by Cyrus to achieve his objectives in the distribution of weapons to the commoners in Xenophon's Cyropaedia. This episode is a key instance in the Persian prince imperial project -Cyrus intends to arm the auxiliaries, equating their military situation with that of the homótimoi. This change will enable the commoners to access to prizes and political positions, which will represent an intense sociopolitical reform. Undertaking a detailed study of the above mentioned sections, I will show what conception of justice operates behind Cyrus project, how he accomplishes his envisioned goals, and what image of ruler embodies the Persian prince.
\end{abstract}

Key-words: Xenophon, Cyropaedia, politics, social reforms, Socratics.

No es arriesgado sostener que, más allá de los múltiples meandros a partir de los que se desarrolla la historia, a los ojos de todo analista existen sucesos o situaciones pivote, que a modo de hito permiten marcar un momento a partir del que es posible señalar cambios rotundos. El registro de esa marca, que señala el antes y el después, se encuentra presente ya en las reflexiones políticas de la Grecia Clásica, tanto en las que atañen a coyunturas históricas como las que refieren a ejercicios o propuestas de cuño irrealista. Del mismo modo que Aristóteles señala en su Política el momento clave en donde el pueblo ateniense dejó de elegir buenos líderes y pasó a dejarse guiar por demagogos (1274a11-15), podemos encontrar a Platón marcando el momento en que se emprende la decisión de purificar la ciudad en República (373a), o la llegada de Busiris al poder en la descripción del Egipto mítico que realiza Isócrates en su Busiris (11). Efectivamente, la filosofía clásica es también fundacional, para la tradición, en ese empeño por encontrar instancias parteaguas que faciliten una reflexión eficaz.

Es de estricta justicia señalar que la Ciropedia de Jenofonte comparte, junto con la República y las Leyes de Platón, el podio de las obras políticas del grupo socrático. De forma novelada (Tatum 1989: 37-66, Stadter 1991, Létoublon y Montanari 2006), Jenofonte se propone en esta obra investigar lo que señala como una excepción, un personaje que puede servir para configurar un programa político: en un mundo donde la inestabilidad signa el gobierno del hombre por el hombre, Ciro destaca por haber logrado conformar un Imperio marcado por la sumisión voluntaria (I.1.1-4) ${ }^{2}$. El recorrido que Jenofonte traza con Ciro es relativamente simple, y a muy grandes rasgos se puede dividir en

\footnotetext{
${ }^{2}$ Para un erudito recuento de la representación de Ciro en la tradición griega dentro de la que se encuentra la Ciropedia, ver García Sanchez (2009: 89-102).
} 
cuatro: educación (Illarraga 2017a), conquista (que ocupa, por mucho, la mayor parte de Ciropedia y tiene múltiples episodios de distinto tipo, atravesando cuestiones políticas, militares y diplomáticas), la organización del imperio, y un epílogo que comienza con el discurso de Ciro de cara a su muerte y cierra con la descripción de la decadencia del Imperio Persa.

La vocación por señalar los hitos antes referidos podría llevar a anotar distintos puntos nodales a lo largo de la obra, lo que podría trivializar esa clase de análisis. Con todo, algunos de los intérpretes más agudos ( $C f$. Nadon 2001: 61 y ss.; Johnson 2005: 182 y ss.; Danzig, 2009), han señalado como indudablemente fundamental un momento de Ciropedia: la reestructuración del ejército -y así, la sociedad-, en el momento de iniciar la campaña contra Asiria que ocupa siete de los ocho libros de la obra, necesaria para poder enfrentarse al extenso poderío enemigo. Esta mutación, que comprende la alteración de los esquemas tradicionales persas descritos en el libro I, será central para los planes militares de Ciro, pero también para sus proyectos políticos ${ }^{3}$.

En este trabajo nos detendremos en el preciso momento en que el príncipe persa decide realizar esta transformación, en pos de indagar qué enseña este cambio sobre la filosofía política jenofontea. En concreto, el momento inicial de la mutación emprendida nos posibilitará abordar los principios que operan detrás de ella, y el modo en que Ciro actúa política y retóricamente para lograr sus objetivos. Si bien esta sección de Ciropedia que se extiende de II.1.5 a II.3.6 ha sido trabajada por algunos de los más relevantes estudiosos sobre Jenofonte, hasta donde llega nuestro conocimiento solo ha sido analizada en minucioso detalle por Christopher Nadon (2001: 61-76) en su influyente Xenophon's Prince. Republic and Empire in the Cyropaedia. Allí el autor entiende la distribución de armas como una de las dos reformas clave (la otra es la introducción de una fuerza de caballería persa) para la persecución de un nuevo régimen político, en un movimiento que busca reformar de forma positiva la tradicional sociedad persa. Efectivamente, el debate sobre la interpretación de este pasaje ha estado centrado en dos puntos: qué rol cumple la distribución

\footnotetext{
${ }^{3}$ Las similitudes entre este reparto de armas y la distribución de armamento a los hilotas en Historia de la Guerra del Peloponeso de Tucídides (IV.80) ha llevado a rápidas identificaciones entre ambos episodios (Cf. Hunt 1998: 203-205). Recientemente Christesen (2006: 48) señala apropiadamente que, en rigor, no es un programa ambicionado por los espartanos, quienes debieron de utilizar esa estrategia movidos por la urgencia de la guerra ( $C f$. Carlier 2010: 341). El lugar de Esparta en el diseño de Ciropedia ha producido un vivo debate que se remonta a la posición extrema de Prinz (1911), quien ha sostenido que Ciropedia es un roman à clef en donde Persia debe ser sustituida por Esparta. Esta posición, rebatida por Scharr (1919), fue luego recuperada en forma más moderada por Luccioni (1949: 9, 32 y ss), Tigersted (1965-1978,1: 159-179) y Georges (1994: 229). Tuplin (2002), ha realizado un análisis sólido y detallado de los vínculos entre la Persia de Jenofonte y Esparta, en donde se descarta una plena identidad. En ese sentido, consideramos que la Ciropedia no intenta traducir el modelo espartano a Persia como modo de apelar a sus contemporáneos, sino que la obra propone un modelo político sui generis (influido indudablemente por ciertas características del sistema lacedemonio).
} 
de armas en el esquema general de Ciropedia y cuál es el lugar que ocupan los protagonistas de este suceso (a saber: Ciro, homótimoi y el pueblo llano). Siguiendo la línea trazada por Nadon y las propuestas de Gabriel Danzig (2009, 2012), sostendremos que este episodio permite a Ciro emprender una reforma largamente ansiada, para lo que debe hacer uso de toda su habilidad política.

Además de habilitar un acceso a los aspectos mencionados de la filosofía de Jenofonte, el recorrido propuesto también nos permitirá presentar un caso específico de un problema caro al pensamiento político del siglo IV a.C.: la posibilidad de emprender reformas sociales en pos de una organización virtuosa. La Ciropedia, por su carácter dramático, permite poner en escena un recuento minucioso de los pasos seguidos por Ciro para modificar la previa estructura militar y, con ella, organización político-social. Esta reforma tendrá como objetivo alterar el rígido esquema persa basado en clases económicas en el que Ciro fue criado, para establecer una nueva jerarquía organizada a partir del actuar virtuoso, arbitrado por el mismo príncipe persa.

\section{EI viejo ejército persa}

La acción que ocupa la parte central de Ciropedia comienza con la iniciativa de Asiria que, junto con sus aliados, se propone la conquista de Media y Persia, pueblos aliados por lazos de amistad y matrimonio. Ciaxares, tío de Ciro y rey medo tras la muerte de su padre Astiages, envía mensajeros a Persia solicitando colaboración militar: es ahí, en I.5.5, donde se conforma el ejército persa que será enviado a la campaña contra Asiria. Esta es la última oportunidad en donde los lectores encontramos el actuar de Ciro delimitado por el sistema político persa. Efectivamente, en el libro I, la descripción del modo de gobierno en Persia contrasta con el despotismo de la rama familiar gobernante en Media (Cf. Tatum 1989: 97 y ss.): los reyes allí desempeñan un papel con peso más simbólico que ejecutivo, restringido a funciones ceremoniales y militares en caso de guerra. Esta forma política, que como ha sido notado se asemeja sugerentemente a la descripción de Esparta realizada por el mismo Jenofonte en La constitución de los Lacedemonios (Tuplin 2002, Cf. Mársico, Illarraga y Marzocca 2017), hace reposar el peso de la autoridad en la ley (que es presentada con cierto tinte ancestral), de quienes son ejecutores los ancianos. A ellos es que llega el pedido de Ciaxares de que Ciro, el príncipe, comande las fuerzas. El medo ya ha visto en acción a Ciro en sus años mozos, y sabe lo decisiva que puede ser su intervención en el campo de batalla. A Ciro no le basta con ser hijo del rey persa Cambises - quien no tiene lugar en la decisión- para ser el líder de la fuerza expedicionaria: son los ancianos reunidos en consejo (hoí bouleúontes geraiteroi, I.5.5.1) quienes lo confirman como general y establecen la estructura 
del ejército enviado. Así, una fuerza de 31.000 infantes,111 1.000 homótimoi y 30.000 del pueblo de los persas (tô̂ demou tôn Persôn, I.5.5.5), es puesta bajo las órdenes de Ciro ${ }^{4}$. Newell (1983: 897-8. Cf. Nadon 2001: 30-9, Reisert 2009: 303) ha señalado sagazmente que no cualquiera ha sido convocado para formar parte de este millar de homótimos. Al contrario, han sido seleccionados por Ciro con cuidado: son sus compañeros, jóvenes educados junto a él, ya en contacto con sus ideas. En su convocatoria, contra toda educación tradicional persa, no está la promesa de practicar la virtud, pero si la de alcanzar riquezas y honores (I.5.12). La construcción e incentivo de esta ambición es clave para Ciro, quien luego la utilizará para apoyar sus reformas.

La distinción entre los llamados pares u homótimoi y el común del pueblo es central para comprender la situación y su posterior desarrollo. En I.2.15 Jenofonte señala que la educación pública descrita en I.2.2-14 se encuentra circunscrita a aquellos que disponen de los medios económicos suficientes. A esa formación, en principio narrada como común a todo el conjunto de la sociedad, solo accede la elite persa:

"Se dice (légontai) que los persas son cerca de ciento veinte mil, y ninguno de ellos es apartado por ley de honores o cargos públicos (oudeis apelélatai nómo timôn kaì arkhôn), sino que todos los persas tienen permitido (éxesti) enviar a sus hijos a las escuelas públicas de justicia (tà koinà tês dikaiosúnes didaskaleîa). Pero (all') solo los que pueden mantener (dunámenoi tréphein) a sus hijos sin trabajar (argoûntas) los envían allí, y los que no pueden no los envían. Los niños que hayan sido educados con maestros públicos pueden pasar su juventud en la clase de los efebos, mientras que los que no han recibido esa educación no pueden. Por su parte, los que hayan cumplido las normas (tà nómina) en la clase de los efebos pueden sumarse a la clase de los adultos, y participar en cargos y honores (arkhôn kaì timôn)...” (I.2.15) .

Los dichos comunes sobre la sociedad persa -suposiciones que asumen un acceso equitativo a los cargos públicos-, recapitulados con la forma "légontai", son firmemente contradichos por Jenofonte con el adversativo "all"”: la educación persa, condición necesaria para formar parte de los órganos de decisión gubernamentales, está abierta solo a una reducida porción

${ }^{4} 200$ homótimos iniciales +4 seleccionados cada uno $(200 \times 4=800$ homótimos $)=1000$ homótimos. 1000 homótimoi x 30 soldados del pueblo llano seleccionados (10 peltastas, 10 arqueros, 10 honderos $)=30.000$ soldados del pueblo llano (10.000 peltastas, 10.000 arqueros, 10.000 honderos). Total del ejército persa enviado: 31.000 soldados (1.000 homótimos, 30.000 soldados del pueblo llano).

${ }^{5}$ A menos que se indique lo contrario, todas las citas y menciones serán a Ciropedia. Se ha seguido la traducción al castellano de Vegas Sansalvador (1987), introduciendo variaciones propias. Cabe señalar que se ha consultado el repertorio de ediciones y traducciones: en el primer caso, las de Gemoll y Peters (1968), Marchant (1970) y Bizos y Delebecque (1971, 1973, 1978); en el segundo, las traducciones al inglés de Miller (1914) y Ambler (2001), al italiano de Ferrari (1995), al francés de Bizos y Delebecque (op.cit), y al portugués de Sano (en prensa). 
de la sociedad, que alcanzarán el estatus de homótimos al llegar a la clase de los adultos. Persia se encuentra, de hecho, divida en dos niveles sociales que comprenden distintas tareas y obligaciones, con una clara diferenciación política que se traduce en la organización militar: en este caso concreto, los 1.000 homótimoi cumplen la función de infantería de élite, mientras que los 30.000 persas restantes, el pueblo llano, son auxiliares de infantería ligera. Al menos, este era el panorama hasta la intervención de Ciro.

\section{Financiar el cambio, convencer a un rey}

Desde II.1.9 a II.1.29 se extiende el punto central de un proceso de reforma del ejército que supondrá también, tras la formación de un Imperio gobernado unilateralmente por Ciro, la implantación por parte del príncipe persa de un sistema político distinto al que funciona en Persia. El sostener aquí la existencia de un vínculo entre mundo militar y mundo político se encuentra especialmente habilitado por la misma estructura de educación y gobierno imperante en Persia, en donde participación gubernamental y entrenamiento militar (y participación en los cuerpos militares relevantes) son los dos rasgos determinantes de aquellos que han atravesado el cursus honorum público. Arkhôn kaì timôn, gobierno y honores (Cf. I.2.15), son el continuum vedado para el pueblo llano, y constituyen factores enlazados en esta Persia sui generis donde, por lo tanto, conforman espacio en donde todo cambio o reforma social impacta de lleno en las dos instancias ${ }^{6}$.

El episodio empieza con lo que, veremos, será una excusa que Ciro maneja magistralmente para llegar a su objetivo: al llegar a Media, Ciaxares reseña una abrumadora cantidad de fuerzas enemigas que hace preciso pensar en una estrategia que logre salvar ese peligro (II.1.5-8). La búsqueda de oportunidades o pretextos, es una de las características señeras de Ciro, quien desde temprana edad aprovecha las situaciones dadas en pos de sus objetivos. Efectivamente, frente a constituir el ejército medo-persa menos de un tercio de las fuerzas de la alianza asiria, Ciaxares solicita a Ciro más efectivos desde Persia. Como ha señalado Nadon (2001: 63), la respuesta negativa del príncipe persa -"...aunque vinieran todos los persas, de todos modos no superaríamos en número a los enemigos (oukh huperbaloímeth'àn toús polemíous, II.1.8.7)"-, no contiene falsedad alguna, pero tampoco un estricto sentido militar, ya que

\footnotetext{
${ }^{6}$ Más allá de esta situación de extrema vincularidad entre gobierno y política dada por la particular estructura social persa, es de notar que la relación no es extraña al texto de la Ciropedia. En VII.1.1-5, Crisantas, homótimos persa y alto mando del ejército aliado medo-persa, de cara a la organización del nuevo Imperio tras la derrota de Asiria, realiza un discurso apoyando la propuesta de Ciro, en donde se traza un paralelo entre el buen ejército y la buena sociedad. No es un detalle dramatológicamente menor, en vistas de la conexión expuesta, que sea precisamente un miembro de los homótimoi quien esboce esta comparación.
} 
en futuras oportunidades de desfavorabilidad numérica Ciro hará un llamado a refuerzos persas ( $C f$. III.2.29, IV.5.16 y ss.). El argumento esgrimido sienta las bases para una contrapropuesta:

"Yo, contestó Ciro, si fuera tú, haría confeccionar lo antes posible (tákhista)
para todos los persas (pâsi Pérsais) que nos van llegando armas (hópla) como
las que llevan cuando vienen de nuestro país los llamados homótimos (hoîáper
ékhontes érkhontai par' hemôn oí tôn homotímon kaloùmenoi); éstas son: una
coraza en torno al pecho, un escudo de mimbre para la mano izquierda y una
daga o un hacha para la mano derecha. Si preparas este equipo, a nosotros
nos harás ir al encuentro de nuestros adversarios con mayor seguridad
(asphalèstaton), y a los enemigos les harás preferir la huida a resistir nuestro
ataque (toîs polemíois dè tò pheúgein è tò ménein airetóteron). Nosotros,
continuó, tomamos posiciones para los que resistan (táttomen dè, éphe, hemâs
mèn autoùs epì toùs ménontas); sin embargo, los que huyan (pheúgosí) os los
asignamos a vosotros y a vuestra caballería (humîn kaì tô̂s híppoís), para que
no les dé tiempo ni de quedarse a esperarnos ni de darse la vuelta (mè skholázosi
méte ménein méte anastréphesthai)" (II.1.9).

Para sortear el inconveniente cuantitativo, Ciro esboza una solución cualitativa, en donde el mejor armamento compensará la falta de números. En los hechos, el príncipe está solicitando a su tío que equipe a los soldados persas a costa de los recursos medos ${ }^{7}$. Al rey medo "le pareció que tenía razón; ya no se acordaba (emémne) de su propuesta de hacer venir más efectivos y preparaba (pareskeuázeto) las armas mencionadas" (II.1.10.1-2). Ciaxares, que como Tatum ha señalado (1989: 115) es una suerte de figura mediocre y viciosa que sirve para contrastar las virtudes de Ciro, es convencido rápidamente por la propuesta de una estrategia que lo aleje del peligro, renuencia a la batalla que será una de sus marcas a lo largo de la campaña. Con las nuevas armas, será el ejército persa quien deba resistir el grueso del ataque, mientras que los medas tendrán como función perseguir a los enemigos en desbandada.

A esta cierta falta de arrojo se suma un grado de ignorancia sobre la sociedad persa, aprovechado hábilmente por Ciro: el participio "llamados" (kaloùmenoi) puede ser leído precisamente en esa línea; con ese agregado, homótimoi no es una descripción de hecho sobre la timé de este grupo, sino una mera nominación. Así, las armas asignadas a ellos no son una prerrogativa a partir de una serie de características individuales, sino que responden a una mera contingencia. En otras palabras, Ciro, señalando la elección institucional de nombrar a los homótimoi como tales desnaturaliza la carga semántica del término; en vez de individuos con rasgos que determinan el uso de cierto tipo de armamento, nos encontramos con un grupo al que se le ha asignado coyunturalmente un rol militar. Precisamente, como esta

${ }^{7}$ Ver supra, n.2.

Araucaria. Revista Iberoamericana de Filosofía, Politica y Humanidades, año 20, n 39 . Primer semestre de 2018. Pp. 109-131. ISSN 1575-6823 e-ISSN 2340-2199 doi: 10.12795/araucaria.2018.i39.06 
designación es arbitraria, es posible extenderla a otros persas, dándole las armas de los homótimoi al conjunto del pueblo: a diferencia de lo que ocurre de hecho, en la presentación de Ciro no hay conflicto con las tradiciones persas. La quita de peso a la cuestión del armamento según el grupo social y el plan táctico que resguarda las fuerzas medas son dos claves para lograr convencer a Ciaxares de financiar el costoso rearme del 96\% (30.000 de 31.000) del ejército ( $C f$. Carlier 2010: 342).

\title{
Convencer a los homótimoi
}

El tiempo de estar fabricadas las armas, los homótimoi llegan a Media encabezando el contingente persa. Ellos serán los primeros interpelados por Ciro: la nueva distribución de armas significa una quita de privilegios, la pérdida de una posición antes exclusiva. El discurso de Ciro, muestra cabal de su destacada destreza política, comienza con un movimiento doble; a la vez que reconoce la valía y ánimo guerrero de los homótimoi, presenta sus inquietudes respecto del trascurso de la batalla impulsada por la diferencia de armamento con los persas del pueblo llano ${ }^{8}$ :

\begin{abstract}
"Amigos míos (ándres phíloi), yo, al veros armados así y preparados en vuestro ánimo (taîs psukhaîs pareskeuasménous) para trabar un combate cuerpo a cuerpo con los enemigos, y sabiendo, por otra parte que los persas que os siguen están armados como para luchar lo más alejados que les sea posible (prosotáto takhthéntes mákhesthai), temí (édeido) que a vosotros, pocos y carentes de aliados (olígoi kaì éremoi summákhon), al caer sobre numerosos enemigos (polemíois polloîs), os ocurriera algún mal (páthoité ti)" (II.1.11).
\end{abstract}

La preocupación por el destino de los homótimoi tiene dos objetivos no declarados que deben ser tenidos en cuenta: la imagen que logra proyectar Ciro sobre sus interlocutores y el lugar que ocupa el miedo como estrategia política. A fines del libro I, Cambises, rey de Persia, le transmite a su hijo lo que considera las claves para ser un buen gobernante; entre ellas, anota la importancia de mostrarse preocupado por el bienestar de aquellos que se encuentran bajo la propia autoridad a fin de ganarse su fidelidad:

"El camino que hay que seguir para hacerse amar (tò phileîsthai) por los gobernados (hupó tôn arkhoménon), cosa que me parece se encuentra entre las cosas más importantes (en tô̂s megístois), evidentemente es el mismo que cuando se desea recibir el afecto (stérgesthai) los amigos (tôn phílon); en efecto, creo que uno se debe mostrar como su protector. Pero, hijo mio, es una tarea dificil, [...] estar dispuesto a ayudarlos (sunepikoureîn) en sus dificultades,

${ }^{8}$ Sobre los distintos aspectos y características de los discursos de Ciro ver Tamiolaki (2016). 
que temes que vayan a cometer un error (phoboúmenon mé ti sphalôsi) y que intentas prevenir (pronoeîn) para que no lo comentan" (I.6.24) ${ }^{9}$.

La reproducción de la propuesta paterna en este caso concreto aparece como una forma cabal para intensificar el lazo entre el príncipe y un grupo que tendrá que reafirmar sus privilegios. La búsqueda de la philía de los homótimoi está acompañada, por otro lado, por un sutil uso del miedo. Para el caso de las relaciones entre pueblos, Lendon (2006: 98) señala la importancia de imponer sophrosúne al enemigo para que, privado de húbris, acepte la dominación. Como muestra el debate con Tigranes de cara al juicio por la revuelta de su padre, el rey armenio (III.1.14-31), la forma más efectiva de volver sóphron a un individuo es el temor. Atentos a esto, es claro que la mención a la gran cantidad de fuerzas enemigas y el contraste con los escasos efectivos propios (recordemos que, de todas las fuerzas medo-persas, solo los 1.000 homótimoi componen la infantería de combate cuerpo a cuerpo) tiene como objetivo mesurar las predisposiciones anímicas mediante el temor y así volverlas sumisas a la propuesta de distribución de armas al pueblo llano. De esta forma, Ciro hace gala de las dos virtudes políticas que se le atribuyen a principio de Ciropedia, la capacidad para generar sumisión voluntaria (I.1.4) y de evitar revueltas gracias al temor (I.1.5), de una forma que Illarraga (2017b) ha investigado para otras secciones de Ciropedia: el uso conjunto de generosidad y coacción a fin de lograr los objetivos deseados.

El cierre del breve discurso de Ciro refuerza la posición privilegiada de los homótimos: si bien los soldados del pueblo tendrán las mismas armas que ellos, se encontrarán en franco desnivel respecto de su conformación anímica. Serán los homótimoi quienes entrenen su valor, quienes deban "afilar sus almas" (tás ge méntoi psukhàs thégein autôn huméteron érgon, II.1.11.7-8). De este modo, Ciro les asegura a sus pares que, si bien los dos grupos estarán pertrechados de igual forma, ellos tendrán preeminencia; es por eso mismo que tienen como la tarea la formación psicológica de los nuevos contingentes: "es propio de un jefe (árkhonntos) no solo presentarse a sí mismo como excelente (agathòn), sino también ocuparse de que sus subordinados (tôn arkhoménon) sean lo mejor (béltistoi) que puedan”. El príncipe persa ha usado la misma estrategia que se mostró efectiva con su tío Ciaxares: a él se le logró atribuir la pesada carga de armar al pueblo de modo que lo viviese como una ventaja para sí mismo; a los homótimoi ahora se le asigna un nuevo y dificultoso deber bajo la reivindicación de su posición dominante.

\footnotetext{
${ }^{9}$ Hacia el final de Ciropedia, Crisantas, uno de los homótimos más importantes para la narración, sostendrá una idea similar a la dicha aquí por Cambises: “...un buen gobernante en nada se diferencia de un buen padre; pues los padres se preocupan de sus hijos para que nunca les falten bienes" (VIII.1.1) 
La propuesta de Ciro es recibida por todos con deleite (hoí d'ésthesan mèn pántes, II.1.12), y un homótimo interviene, disculpándose por el atrevimiento de aconsejar a su príncipe y general, pidiendo que sea Ciro quien entregue las armas a los nuevos soldados del pueblo llano: si es él, hábil en el manejo de los discursos (lógoi), quien reparte el nuevo equipo, el pueblo lo recibirá con mayor alegría (II.1.13). Estas palabras no son triviales ni ingenuas; la excesiva deferencia del homótimo anónimo encubre un claro recordatorio: estrictamente, bajo las normas persas, Ciro es un homótimos designado general, y es solo tras la aceptación de esta clase que puede decidir repartir la renovada panoplia. Así, la cordialidad del anónimo no es otra cosa que una advertencia: solo con la conformidad de los homótimoi se realiza esta mutación. Es en esa misma línea cómo debe ser leída la oración final de su discurso: "No debe faltar (apeînai) nuestra participación (tà hemétera), sino que es absolutamente preciso que estimulemos el espíritu (tò phrónema) de los hombres por cualquier medio. Pues cuanto mejores (beltiones) sean, más útiles (khrésimon) serán para nosotros (hemîn)". El énfasis en la primera persona del plural, junto con el foco en la necesidad de colaboración para la educación anímica del pueblo, remarca que el proyecto debe ser emprendido con el consentimiento y ayuda de los homótimoi.

\title{
Convencer al pueblo
}

Tras convencer a los homótimoi, Ciro se dispone a presentar las armas al pueblo llano. Jenofonte retrata un verdadero espectáculo montado por el príncipe persa; en una muestra claramente teatral, el ejército es convocado plenariamente y las nuevas armas son presentadas frente a los soldados formados, delante de donde Ciro comenzará su discurso.

\begin{abstract}
"Varones persas, vosotros nacisteis (éphute) y crecisteis (etráphete) en la misma tierra que nosotros. Tenéis un físico (tà sómatá) en nada inferior (kheírona) al nuestro, y a vosotros concierne tener un espíritu (psukhás) no inferior al nuestro (oudèn kakíonas). Aun así, en nuestra patria no estabais en igualdad con nosotros (tê patrídi ou meteíkhete tôn íson hemîn), no porque hubierais sido excluidos (apelathéntes) por nosotros, sino porque teníais la necesidad de proporcionaros el medio de vida. Pero ahora, con ayuda de los dioses, yo me preocuparé (emoì melései) de ello: es posible para ustedes, si lo desean, tengáis armas como las que nosotros tenemos (labóntas hopla oiàper hemeîs ékhomen) a fin de embarcarse en los mismos peligros que nosotros (eis tòn autòn hemîn kìndunon embaínein), así, si algo hermoso y noble aconteciese (toúton kalòn kagathòn gígnetai), seríais merecedores de las mismas cosas que nosotros (tôn homoìn hemîn axiô̂sthai)" (II.1.15) ${ }^{10}$.
\end{abstract}

${ }^{10} \mathrm{Si}$ bien sería trivial resaltar la relevancia del ejercicio de traducción, es de resaltar que todas 
Ciro comienza mostrando las semejanzas entre el pueblo llano y el grupo homótimo al que él mismo pertenece, en una apelación a la buena voluntad, más caracterizada por la generosidad que por su rigurosidad. Estamos nuevamente frente a un intenso ejercicio de persuasión, ya practicado con eficacia frente a los homótimoi. La insistencia en el recurrir a verbos que tengan relación con el crecimiento (phúo, trépho) y no con la educación formal cobra sentido frente a la imposibilidad para poder acceder a la educación pública persa descrita en I.2.1-14 (Cf. I.2.15): estrictamente, lo único que hermana a todos los persas es el suelo en donde nacieron. La referencia al cuerpo también entra dentro de estas estrategias retóricas que buscan ganarse la buena voluntad de cara a la propuesta de Ciro: si tenemos en cuenta que los homótimoi pasan su vida entrenando militarmente, alimentados con una dieta especialmente pensadas para tal fin, y que los individuos del pueblo son aquellos que precisan trabajar para sobrevivir, estrictamente no hay igualdad alguna. Johnson ha sostenido lo contrario, afirmando que "we are told of no special training in such fighting, for the peers' superiority here consists in their strenght of character, not in any technical skill" (2005: 183), pero esta afirmación es extraña habida cuenta de la mención que hace Jenofonte al intenso entrenamiento durante largos años (durante las clases de efebos y de adultos) ${ }^{11}$, en forma de competencias intrageneracionales, de tareas policiales, de partidas de caza y de expediciones militares (I.2.9-13), instancias que aseguran efectivamente una diferenciación técnica en cuestiones bélicas. En su discurso, el príncipe persa debe olvidar estas distancias entre homótimoi y pueblo llano, y construir una imagen en donde se borren todas las consecuencias negativas del nuevo armamento -en rigor, de estar alejados de la refriega, los soldados pasarán al centro de la batalla a cumplir un rol para el que no tienen ninguna preparación física o anímica. Ciro no puede evitar poner énfasis en la necesidad de entrenarse psicológicamente, pero sí puede intentar deflacionar el riesgo pintando una imagen favorable en cuento a lo técnico y lo físico.

Ciro no oculta las diferencias en la estructura social de Persia, pero insiste en que ellas no son responsabilidad de los homótimoi, esto es, de los beneficiados por el sistema persa. Aquí entra en juego qué lectura se realice sobre la posición de Ciro con respecto a Persia y, muy especialmente, del famoso pasaje de los niños y sus túnicas (I.3.16-17). En un debate aún activo, que constituye uno

las traducciones a lengua moderna (ver supra, n.3) difieren sensiblemente en este importante pasaje. Ello no parece tener relación con la complejidad gramatical de la sección, sino con su relevancia. Las variaciones de más peso de nuestra versión, respecto de la traducción de Ana Vegas Sansalvador editada por Gredos, se encuentran en la primera y última línea del parágrafo: el verbo trépho fue traducido como "crecer" y no como "ser educado", dado que precisamente lo que distingue a los comunes es no haber recibido educación formal; por otro lado, la preposición eis fue interpretada como introduciendo finalidad o propósito, con el kai subsiguiente en sentido epexegético, para mostrar la relación causal entre las armas entregadas y el reparto equitativo de honores.

${ }^{11}$ Para un esquema preciso de las edades en la educación persa, ver Tuplin (2002: 153). 
de los nodos centrales para la lectura de Ciropedia, un importante número de especialistas con los que coincidimos ha sostenido que esa sección da cuenta de la fuerte posición crítica del príncipe persa para con el concepto imperante de justicia patria ${ }^{12}$. En Persia la justicia es entendida estrictamente como respeto a la legalidad imperante aun cuando esta atente contra la mejor convivencia o desarrollo, mientras que Ciro sostiene la necesidad de vulnerar ley y propiedad en pos de lograr una sociedad más eficiente. Durante este discurso, rodeado de sus colegas homótimos intensamente educados bajo la noción legalista de justicia por él criticada, Ciro no puede ir más allá. En la oportunidad de los niños y las túnicas, es el mismo Ciro niño quien interviene para reorganizar la propiedad del mejor modo posible; en este momento también sobre él ("emoi") reposa todo el peso de la decisión redistributiva. La alusión a los dioses, figura retórica común, también esconde el peso individual de Ciro: para homótimoi y soldados del pueblo llano es una muestra de piedad, pero como lectores estamos advertidos desde los consejos de Cambises a su hijo que los dioses solo ayudan a quienes se ayudan a sí mismos (I.6.6). En su discurso, Ciro no hace otra cosa que posicionarse como garantía de una transformación inminente, una redistribución que encuentra excusa para alterar el orden dado: si los soldados del pueblo llano están dispuestos a pasar por los mismos peligros que los homótimoi (aunque no tengan la misma formación), tendrán iguales recompensas.

El discurso continúa en la misma tónica. Ciro resalta que pueden existir diferencias en la habilidad de los individuos del pueblo y homótimos por el tiempo dedicado a la práctica, pero que las armas serán iguales para todos y agrega:

\begin{abstract}
“Así que con estas armas, ¿en qué podríamos diferenciarnos unos de otros (éteros etérou diaphéroi), excepto en el arrojo (tólme)? Os conviene alimentarlo ((hupotréphesthai) no menos que a nosotros. En efecto, respecto a la victoria (níkes), que es la que obtiene y protege las cosas hermosas y nobles (tà kalà pánta kaì tàgathà ktâtaí te kaì sózei), ¿por qué nos preocuparía (prosékei) más a nosotros que a vosotros?, y, en cuanto al poder (krátous), que otorga a los fuertes todo lo de los débiles (hò pánta tá tôn hettóvon tô̂s khreìttosi doreîtai), ¿por qué lo necesitaríamos más nosotros que vosotros? [...] Habéis oído todo lo que he dicho; veis las armas, y el que lo desee (khrézon) que las tome y se inscriba ante el taxiarco en la misma compañía que nosotros, pero al que le baste estar en el puesto de mercenario (en misthophórou khóra) que se quede con las armas de los subordinados (huperetikoîs hóplois)" (II.2.17-18).
\end{abstract}

\footnotetext{
${ }^{12}$ Notablemente, Nadon (2001) y Danzig (2009) han sostenido esta lectura, viendo en este episodio la primera aparición de la posición de Ciro en torno a la justicia. Para la lectura que ha entendido que ese pasaje muestra cómo Ciro aprende y se ajusta la justicia tradicional persa, ver Luccioni (1947: 65) y Gera (1993: 74 y ss.).
} 
La primera pregunta ya la ha contestado con antelación el mismo príncipe persa: a las armas y al ánimo es preciso agregar el entrenamiento. Esa precisión debe ser eliminada de la sección del discurso para que sea efectivo. El énfasis está puesto en una disposición anímica, que puede mudar más rápidamente que la habilidad adquirida mediante el entrenamiento somático: en esta exposición, tólma es, antes que una configuración estable de la psicología de un individuo, un estado dinámico del ánimo. A partir de esta clave debemos entender la mención a la persecución de la victoria y la búsqueda de poder, ya que son las que activan y mueven la audacia en el campo militar. Existiendo aquellas, existe esta, y así se desdibujarían las diferencias entre pueblo y homótimoi.

El discurso de Ciro es increíblemente efectivo. Ha sido concesivo con los miembros del pueblo llano, ha resaltado virtudes inexistentes, ha presentado garantías para enormes beneficios y ha sido particularmente agresivo con aquellos que rechacen las nuevas armas -solo los cobardes desearían las armas huperetikoís-. Finalmente, lo que pesa es la promesa del ascenso por mérito, ya que "si siendo invitados a obtener las mismas ventajas por pasar fatigas semejantes (tà hómoia ponoûntes tôn autôn tugkhánein), no desearan (ethelésousi) hacerlo, en justicia (dikaios) vivirían sin recursos durante toda su vida" (II.1.19). Ciro sutilmente ha dejado entrever que el esfuerzo no será el mismo, por entrenamiento y disposición, para homótimoi y soldados del pueblo, pero hay un cambio notable. La posibilidad de entrar al grupo que accedía a cargos y honores (timoí kai arkhoí. Cf. I.2.15) estaba vedada de hecho por no haber tenido los recursos como para asistir a las escuelas que dan inicio al cursus honorum persa; ahora, en contexto de guerra, Ciro garantiza una nueva forma de vida que permitirá alcanzar lo antes reservado para los homótimoi. Más allá de las medias verdades y giros persuasivos del príncipe persa hay una realidad patente: ahora los miembros del pueblo tendrán más posibilidades de acceder a lo otrora vedado.

\section{Primera convivencia}

La campaña militar no empieza tras este reparto, y Ciro utiliza el tiempo disponible para entrenar física y psicológicamente a los nuevos soldados ("tà sómata tôn meth' eautoû eìs iskhún, didáskein dè tà taktiká, thégein dè tàs psukhàs eìs tà polemiká" II.1.20). En estos ejercicios, que comprenden la práctica en las distintas nuevas armas como también el adiestramiento anímico, cumplen un rol fundamental los homótimoi. Ellos, que ocupan en este primer momento las posiciones intermedias y altas de comandancia ${ }^{13}$, son

\footnotetext{
${ }^{13}$ No está anotado con precisión, pero contemplando lo dicho en II.2.22 respecto de los oficiales y los números de I.5.5 (ver supra, n.3), se nos habilita a suponer que buena parte de los oficiales 
modelo de emulación de los hombres en una serie de competencias inter-pares establecidas por el príncipe persa (agônás te autô̂s proeîpen apánton hopósa egígnosken askeîsthai agathòn eívai hupò stratiotôn kaì proeîpe táde, II.1.22). De esta forma, Ciro instituye para los soldados del pueblo la misma dinámica que la educación persa impone a los efebos (I.2.12), reponiendo esa instancia de aprendizaje. Sugerentemente, la noción de la competencia como modo de alentar el desarrollo de habilidades que contribuyan al desarrollo del grupo al que pertenecen los competidores es una idea no solo repetida por Jenofonte en la misma Ciropedia, sino también en La constitución de los lacedemonios (II.6-18, IV.2-5). También Ciro replica en la organización castrense una de las más distintivas marcas de la educación persa (y de la organización espartana): la convivencia común (II.2.25-29. Cf. I.2.3-4). Con el mismo criterio que el aplicado en la eleuthéra agorá de Persia, la intención de este espacio compartido es alentar las prácticas y modos instituidos mediante el control de todos por todos: cada uno de los soldados es juzgado por su comportamiento, pero también es juez del de los otros. A su vez, el compartir la vivienda colabora con el conocimiento de la tropa, y establece lazos de solidaridad útiles en tiempos de guerra (II.2.26-28).

\title{
Nuevos problemas distributivos
}

En una cena de las habituales en la gran tienda de campaña de Ciro, luego de una serie de bromas sobre la convivencia entre homótimoi y los recientemente incorporados (II.2.2-18), el homótimo Crisantas -personaje de cierta importancia en Ciropedia - interviene para dar su opinión sobre un tema adelantado en el discurso a los soldados del pueblo llano, el reparto de lo obtenido en las posibles victorias:

\begin{abstract}
"Yo considero que han venido con nosotros los mejores hombres (beltíones), y también otros de menos valía (meíonos áxioi), pero si algo bueno llegase a pasar (ti génetai agathón), demandarán (axiósousin) todos ellos participar por igual de él (isomoireîn). No obstante, yo, por mi parte, considero que en asuntos humanos no hay nada menos equitativo (oudèn anisóteron) que considerar igual al malo y al bueno (tôu íson tón te kakòn kaì tòn agathòn axioûsathai)" (II.2.18).
\end{abstract}

de los dos escalafones superiores (que comandan unidades de 30 hombres o más) son homótimoi. Esquematizando esto:

${ }^{(i)}$ pémpada: cinco hombres, a cargo del pempadarco (oficial del pueblo llano)

(ii) década: diez hombres, a cargo del decadarco (oficial del pueblo llano)

(iii) lokhagogós: alrededor de 30 hombres, a cargo del lóchos (posiblemente oficial homótimo, alrededor de 1000 oficiales de esta categoria en el ejército)

(iv) táxis: mil hombres, a cargo de taxiarco (oficial homótimo, 30 oficiales de esta categoría en el ejército)

Araucaria. Revista Iberoamericana de Filosofía, Politica y Humanidades, año 20, n 39 . Primer semestre de 2018. Pp. 109-131. ISSN 1575-6823 e-ISSN 2340-2199 doi: 10.12795/araucaria.2018.i39.06 
Crisantas habla por el privilegio perdido de sus pares. Intenta encubrir con delicadeza y cortesía el temor a un reparto que, plenamente equitativo, desoiga el mérito en batalla de cada individuo. La asunción tácita que desencadena este miedo es clara: los homótimoi, con mejor entrenamiento, combatirán mejor, pero pese a ello no se verán recompensados. Para sorpresa de Crisantas, Ciro propone debatir en una asamblea del ejército (embaleîn peri toútou boulèn eis tò stráteuma, II.2.18); el homótimo insiste en que puede instituir el reparto por mérito unilateralmente, de la misma forma en que instituyó las competiciones entre soldados, con sus respectivos premios ${ }^{14}$. La respuesta de Ciro a esta reclamación mumestra el tacto político del príncipe persa: los casos no son iguales, ya que lo obtenido en la campaña militar no será considerado un favor dado por el comandante, sino un bien común al ejército (II.2.19). Crisantas parece entender el punto, pero vuelve a insistir, ¿hay seguridad de que los soldados del pueblo (cuyos votos son, por lejos, decisivos) decidan repartir las ganancias según lo realizado, y no en partes iguales?

"Yo, respondió Ciro, creo que sí, en parte porque somos nosotros quienes lo recomendamos (hemôn sunagoreuóvton), y en parte porque es vergonzoso decir lo contrario (aiskhrón òn antilégein): que quien soporta las máximas fatigas y rinde el máximo servicio a la comunidad no merezca también las máximas recompensas (megìston axioûsthai). Y creo, prosiguió, que incluso a los peores les parecerá claro acordar que los mejores tengan mayor beneficio" (II.2.20).

El príncipe persa tiene la seguridad de que su propia opinión pesará lo suficiente como para convencer al pueblo llano, y también confía en que la vergüenza hará su parte. Esa última idea es propia de la educación persa, que aquí Ciro vuelve una suerte de patrón humano: el pundonor evita que un individuo emprenda acciones consideradas negativas de haber un cuerpo que pueda observarlas y evaluarlas (I.2.3, I, 2.8). Pero hay un dato más, sumado por el no siempre declarado narrador de Ciropedia: Ciro desea llevar adelante la votación porque sabe que los homótimoi temen el posible resultado de quedar excluidas sus ganancias en caso de ganar la opción de reparto equitativo (II.2.21). El príncipe persa se distancia de su propia clase, como ya ha hecho a la hora de convencerlos de la conveniencia de repartir las armas; ahora desea que se sientan observados y juzgados, ya que así serán mejores. Así, la votación que es presentada a los homótimoi como una manera de salvar la dificultad de imponer el reparto por mérito a los soldados pertenecientes al pueblo, es

\footnotetext{
${ }^{14}$ Es de señalar la semejanza entre las competiciones instauradas por Ciro en este momento y el episodio relatado por el mismo Jenofonte en Helénicas (III.4.15-19) y Agesilao (I.28), donde el rey espartano organiza juegos con el mismo objetivo aquí presentado: ejercitar a las tropas para mantener su preparación frente al inminente conflicto, y estimular su competencia frente a la perspectiva de obtener premios y honores. Frente a estas semejanzas en dos gobernantes encomiables para Jenofonte, podemos afirmar que nos encontramos ante una práctica indudablemente positiva.
} 
presentada también como una estrategia política de cara a ellos mismos, en pos de afianzar su sometimiento (Cf. Field 2012: 728-729).

Un día después el ejército se vuelve a reunir. Es la segunda vez que Ciro convoca a sus fuerzas para un discurso, la primera desde que su estructura ha sido reformada. La ocasión indudablemente tiene capital importancia; además de tocarse un tema clave como el reparto del botín, se pondrá a prueba el dominio político que Ciro tiene sobre sus hombres. Antes de abrirse el debate el príncipe realiza una introducción. Allí expone la importancia de la victoria y da cuenta de la importancia de cada individuo en ella: el resultado de la guerra está atravesado por la decisión personal de cada soldado en esforzarse todo lo posible (II.3.3). Ello le permite a Ciro abrir la pregunta por la distribución de futuros honores y bienes cambiando la óptica hasta ahora esperada; no se plantea la eventual justicia del reparto de ca cara a los posibles méritos, al contrario, se evalúa en la presente utilidad en pos de derrotar al enemigo $(C f$. Iglesias Zoido 2003: 164):

“...que uno de vosotros se levante aquí y responda esta pregunta solamente: en qué caso cree que se ejercita mejor el valor (tèn aretèn) entre nosotros, cuando el que desee esforzarse más y exponerse a los mayores peligros (ho pleîsta kaì poneîn kaì kinduneûein) obtiene también los mayores honores (pleístes kaì timês), o cuando sabemos que no tiene diferencia ser mal soldado (oudèn diaphérei kakòn eínai), pues al final obtendremos lo mismo todos por igual (homoíos gàr pántes tôn íson)" (II.3.4).

Dos oradores levantarán el guante arrojado por Ciro y responderán a su pregunta: Crisantas por los homótimoi y Feraulas por el pueblo. A Crisantas ya lo hemos oído exponiendo sus preocupaciones respecto a la distribución. Convencido por Ciro, ahora habla apoyando su proyecto (Carlier 2010: 342). Su breve intervención tiene dos instancias para sostener el reparto por méritos. Primero, descarta que la consulta del príncipe persa sea tal; sostiene, en cambio, que es una manera de probar si hay hombres en el ejército que deseen recompensas sin haber realizado acciones virtuosas (II.3.5). Luego, cierra sus palabras posicionándose dentro de los menos favorecidos; él pertenece al grupo de quienes, aún sin tener las condiciones para sobresalir en batalla, desea que quienes lo hagan sean recompensados. La razón se encuadra dentro del esquema expuesto por Ciro: de existir incentivos para las buenas acciones, se podrá alcanzar la victoria, y en ella será recompensado en la medida que corresponda; por el contrario, de no existir nada que aliente el esfuerzo individual la derrota será más posible, y allí todos obtienen la peor de las partes, la esclavitud (II.3.6. Cf. II.3.3).

Para representar al pueblo interviene Feraulas, personaje que a partir de esta aparición cobrará un lugar destacado dentro de la obra. En la presentación 
que realiza Jenofonte, además de decírsenos que era un hombre noble de cuerpo y alma (kaì tò sôma kaì tèn psukhèn ouk agennê̂ andrì eoikós, II.3.7.23), se nos informa de un dato particularmente interesante: Feraulas formaba parte del oîkos de Ciro (Kúro pos éti oíkothen sunéthes, II.3.7.2). Jenofonte no es ingenuo; su gran experiencia política en órganos de participación directa indudablemente lo ha puesto en contacto con una realidad patente: las deliberaciones que se presentan como abiertas bien pueden encubrir decisiones ya tomadas, resueltas previamente y operadas para alcanzarse en la instancia de exposición común. La mención a los vínculos estrechísimos entre Ciro y Feraulas debe ser leída a esa luz, que sirve como anticipo: la exposición del representante del pueblo también apoyará lo sostenido por el príncipe persa.

Tras una introducción en donde afirma que todos en el ejército tienen la común obligación de obedecer a los jefes, y que todos estiman como lo más positivo la resolución en batalla, el portavoz del pueblo presenta la razón por la que cree que los beneficios posibles deben ser repartidos por mérito. El razonamiento de Feraulas está organizado de modo que niegan exista una diferencia con los homótimoi. En ese sentido, el objetivo de su discurso es convencer a sus compañeros: son ellos los que precisan aceptar el beneficio de ser medidos a la par que los homótimos. El primer argumento, que llamaremos "de lo connatural de la lucha" (II.3.9-11), apunta a mostrar cómo atacar y defenderse son actividades propias de todo hombre. Una serie de analogías con el mundo animal es reforzada por un uso en extremo intenso de distintas formas del término phúsis (phúsei, II.3.9.1; pará tês phúseos, II.3.9.3; parà tês phúseos, II.3.10.6; hupò tês phúseos, II.3.10.8; phúsei, II.3.10.9). Esta perspectiva borra las diferencias desarrolladas a partir del entrenamiento, homogeneizando a toda la fuerza militar persa. Pero esta visión que deja en pie de igualdad a homótimoi y pueblo llano será rápidamente desarticulada por un argumento referido a la vida transitada por cada uno de los grupos. Feraulas mantiene que los individuos del pueblo están en mejores condiciones para enfrentar los peligros de la guerra pues ellos han vivido una vida ardua y pesarosa, experiencia difícil no transitada por los homótimos. Antes fue olvidado el entrenamiento militar homótimo; ahora no se desconoce su formación llena de privaciones, sino que se la minimiza:

\footnotetext{
"Sé que éstos se jactan (méga phronoûsin) de que han sido educados (pepaídeuntai) para soportar el hambre, la sed y el frío (kaì pròs limòn kaì dípsan kaì pròs gîros kartereîn), ignorando que también nosotros hemos sido educados para estas privaciones por un maestro más poderoso (kreittonos didaskálou) que ellos, porque no hay ningún maestro mejor que la necesidad (tês anágkes), que nos enseñó el conocimiento muy preciso de esto (kaì lían taût' akriboûn edídaxe)" (II.3.13).
} 
Naturaleza (phúsis) y necesidad (anágke) son presentadas como un recurso poderoso: son fuerzas que superan de lleno cualquier capacidad humana, y en eso radica su efectividad para desarticular la importancia de la formación humana. Todas las privaciones que han vivido los homótimoi por sus maestros no se comparan con las impuestas por la potencia de la necesidad. Siguiendo este razonamiento, todo reparto por mérito favorecerá sin duda al pueblo. Lo que estimula (parormâ, II.3.12.2) a Feraulas a sumergirse en esta contienda por el reparto del botín y los honores es que Ciro será el garante de un juicio justo. $\mathrm{Al}$ contacto personal (que permite a Feraulas jurar por los dioses) se suma algo que todos han vivido: fue Ciro quien decidió repartir las armas, equiparando pueblo llano a homótimoi.

Finalmente, todas las partes involucradas en el debate obtienen lo que quieren, que es a su vez lo planeado por Ciro: "Se decidió que cada uno recibiera los honores que mereciera (tèn axían timâsthai ékaston), y que Ciro fuera el que juzgue (tòn krínonta eínai). En efecto, de esta forma procedieron sobre esto" (II.3.16). Homótimoi y soldados del pueblo lograron obtener lo que Crisantas y Feraulas solicitaron, entendiendo cada uno a su grupo como el más capaz: ser evaluados según su mérito. Como el discurso de Feraulas desnuda, detrás de la noción de merecimiento se encuentra un claro egoísmo asentado en la convicción de la propia superioridad. Ciro también logró su objetivo: evitar una controversia innecesaria que mine su poder. Al contrario, el príncipe persa se posicionó como el árbitro indiscutido del ejército, ya no asignado por la ley persa, sino con el consenso de homótimoi y pueblo llano.

\section{Conclusión}

En uno de los trabajos más importantes sobre la cuestión de la justicia y redistribución en Ciropedia, Gabriel Danzig (2009) ha sostenido, a partir de un análisis detallado del episodio de los niños y sus túnicas, que el programa imperial de Ciro está signado por la persecución del establecimiento de un orden político redistributivo y meritocrático, en lo que puede entenderse como una crítica al estructurado sistema persa ( $C f$. Illarraga, 2017). En buena medida, este trabajo ha señalado la forma en que una transformación que propenda a ese modelo debe ser implementada. En una mirada crítica de este proceso, Johnson (2012) sostiene que el establecimiento de un sistema basado en el mérito va en contra del igualitarismo persa y perjudica a los homótimoi sin beneficiar al pueblo, en un movimiento que busca reemplazar virtud por obediencia o lealtad. Como Danzig (2012: 501 n. 8, 514) ha señalado, Johnson olvida que la obediencia o el sometimiento son también formas inferiores de virtud (Cf.VIII.1; Mem. IV.4), instancia que ha sido estudiada para las relaciones internacionales 
(Lendon, 2006). También Nadon (2001: 40) ha mostrado cómo la reforma emprendida por Ciro amplía las posibilidades sociales para el desarrollo de la virtud, como muestra el caso de Feraulas, quien solo podrá avanzar en ese sentido a partir de las reformas llevadas adelante por el príncipe persa. A su vez, esta virtud, como marca Newell (1983: 898), ha alterado su sentido, ya no es la misma practicada en Persia (Cf. Farber 1979: 501): con la reforma emprendida, los tiempos de guerra y conquista permiten a los miembros del pueblo llano obtener los medios de sustento que antes carecían, abriendo las oportunidades a aquellos antes excluidos por el sistema persa pero mutando, de esta forma, el proceso por el cual se desarrolla la virtud.

Como hemos visto, la reforma altera radicalmente el panorama político y social que rodea a Ciro y, si tenemos en cuenta que el ejército será la base para la fundación de su sociedad imperial, este cambio trastocará definitivamente el escenario persa ${ }^{15}$. En concreto, el príncipe persa desorganizará el sistema de privilegios basado en clases económicas en que se funda la división entre homótimos y pueblo: la entrega de armas es la condición para un reparto homogéneo de tareas $\mathrm{y}$, por lo tanto, también de honores y cargos a partir de la evaluación de los méritos individuales. Esta reconstrucción políticosocial lleva, en cierto modo, el criterio persa al extremo: la virtud ya no será examinada solo entre los homótimoi, sino que será considerada para todo miembro de la sociedad que desee que su actuar sea considerado. Detrás de esta mutación se encuentra el criterio de justicia distributiva que Ciro ya presentó cuando niño: solo poniendo en paridad de condiciones materiales a los distintos individuos es posible programar una sociedad justa. Esa es precisamente la tarea del gobernante, que Ciro emprende con decisión poniéndose en un lugar privilegiado: no solo será él quien logrará, por su habilidad y genio, las condiciones para realizar la distribución de armas, sino que también quedará en la posición de arbitrar el reparto de futuros premios y cargos. En la persecución de esa posición, el príncipe persa hace gala de una notable capacidad retórica y política: sabe evaluar los objetivos de cada individuo (Ciaxares) o grupo (homótimoi, pueblo llano) para, haciendo uso de su sagacidad y habilidad discursiva, orientar el curso de los hechos hacia el lugar por él deseado ${ }^{16}$.

De esta manera, las modificaciones emprendidas por Ciro en los pasajes trabajados en este artículo constituyen un plan detallado y preciso de uno de los problemas del pensamiento político del siglo IV.a.C y, en particular, de las filosofías socráticas: la viabilidad de cambios radicales en las estructuras

\footnotetext{
${ }^{15}$ Jansen (2012: 755-756) ha anotado incluso que, miradas en clave amplia, estas reformas de Ciropedia pueden funcionar como una exposición narrativa más amplia de las reformas que Jenofonte plantea en Ingresos para Atenas.

${ }^{16}$ No hay sido nuestro objetivo en este trabajo recorrer la teorización jenofontea sobre el líder, sino indagar de qué manera se lleva adelante una reforma militar de vital importancia y qué significa en el concierto de Ciropedia. Para el problema del liderazgo, ver Wood (1964), Gray (2011, cap.5), Sandridge (2012) y Buxton (2017: 325-329).
} 
políticas sociales. En el protagonista de Ciropedia Jenofonte logra construir un modelo especialmente complejo en donde logran convivir el claro objetivo por establecer un régimen que mida la virtud (antes acumulación de riquezas) con un pragmatismo descarnado y una fuerte ambición. En este sentido, el reparto de armas al pueblo presenta de forma reducida una respuesta a la pregunta de los socráticos por la política: si se desea una sociedad orientada hacia la virtud es preciso un gobernante como Ciro -con poder y habilidad para establecerse como una autoridad incuestionable y con la ambición que lo mueva a utilizar los medios necesarios en pos de objetivos virtuosos.

Así, el episodio analizado tiene una doble lección que brindarle al lector de Ciropedia. La primera y más visible refiere a las prácticas políticas y retóricas precisas para concretar el plan mentado, los medios precisos para los fines establecidos. En este sentido, nuestro estudio ha recorrido toda la serie de elementos presentados por Jenofonte: la detección de ambiciones, deseos y temores, esto es, de la situación psicológica de los sujetos; la presentación habilidosa del propio proyecto; y el aprovechamiento de la ocasión justa, del momento propicio. La segunda lección, íntimamente relacionada con la primera, habla del desolador lugar del gobernante eficaz: con la firme convicción -que, como lectores, Jenofonte nos ha presentado como correcta y además exitosade la potencia de su proyecto político, Ciro emprende cada decisión desde la más estricta soledad. Aparentemente rodeado de colegas y consejeros, el príncipe persa lleva adelante un proyecto personal que, en el límite, se sostiene en el peso de su autoridad indivisa. En este sentido, el reparto de armas en la Ciropedia nos muestra un aspecto fundamental de la concepción del gobernante ideal para Jenofonte: quien se encuentra en el pináculo de la estructura política no solo debe tomar las decisiones aislado, sino que debe buscar constituir ese espacio de forma que pueda ser habitado solo por él mismo. La soledad del poder es, en la punta de la jerarquía, una condición esencial para la efectividad política. 


\section{Referencias bibliográficas:}

Ambler 2001: Ambler, W., Xenophon. The Education of Cyrus (Ithaca, 2001). Bizos 1971: Bizos, M., Xénophon. Cyropédie. Tome I. (Paris, 1971). Bizos 1973: Bizos, M., Xénophon. Cyropédie. Tome II. (Paris, 1973).

Buxton 2017: Buxton, R., "Xenophon on Leadership: Commanders as Friends", Flowers, M. (ed.), The Cambridge Companion to Xenophon (Cambridge, 2017).

Carlier 2010: Carlier, P., "The Idea of Imperial Monarchy in Xenophon's Cyropaedia", Gray, V. (ed.), Oxford Readings in Classical Studies (Oxford, 2010).

Chistesen 2006: Chistesen, P., “Xenophon's 'Cyropaedia' and Military Reform in Sparta", The Journal of Hellenic Studies, 126, 47-65.

Danzig 2009: Danzig, G., "Justice and Lay in Xenophon's Cyropaedia and Memorabilia", Pólis, 26, 242-266.

Danzig 2012: Danzig, G., "The Best of the Achaemenids: Benevolence, Self-Interest and the 'Ironic' Reading of Cyropaedia", Hobden, F. y C.Tuplin, Xenophon: Ethical Principles and Historical Enquiry (Leiden/Boston, 2012).

Delebecque 1978: Delebecque, E., Xénophon. Cyropédie. Tome III. (Paris, 1978).

Due 1989: Due, B., The Cyropaedia. Xenophon's Aims and Methods (Aarhus, 1989).

Farber 1979: Farber, J., "The Cyropaedia and Hellenistic Kingship", The American Journal of Philology, 100, 497-514.

Ferrari 1995: Ferrari, F., Senofonte. Ciropedia (Milano, 1995).

Field 2012: Field, L., "Xenophon's Cyropaedia: Educating our Political Hopes", The Journal of Politics, 74, 723-738.

García Sánchez 2009: García Sánchez, M., Formas de representación de la alteridad persa en el imaginario griego (Barcelona, 2009).

Gemoll y Peters 1968: Gemoll, W., y J. Peters, Xenopontis Institutio Cyri (Göttingen, 1968).

Gera 1993: Gera, D., Xenophon's Cyropaedia: Style, Genre, and Literary Technique (Oxford, 1993).

Gray 2011: Gray, V., Xenophon's Mirror of Princes: Reading the Reflections (Oxford, 2011).

Hunt 1998: Hunt, P., Slaves, Warfare and Ideology in the Greek Historians (Cambridge, 1998). 
Iglesias Zoido (2003): Iglesias Zoido, J., "La arenga militar en Jenofonte a propósito de Ciropedia 3.3.48-55", Norba. Revista de Historia, 16, pp. 157-166.

Illarraga 2017a (en prensa): Illarraga, R., "El extraño reino de un joven príncipe. Política, educación y justicia en la sociedad persa de la Ciropedia (1.2.2 16)", Quaderni Urbinati di Cultura Classica.

Illarraga 2017b (en prensa): Illarraga, R., "Crisis política y su resolución en la Ciropedia: el caso de Armenia y Caldea (2.4.12-3.1.1)", Eidos.

Jansen 2012: Jansen, J., "Strangers Incorporated: Outsiders in Xenophon's Poroi", Hobden, F. y C.Tuplin (eds.), Xenophon: Ethical Principles and Historical Inquiry (Leiden/Boston, 2012).

Johnson 2005: Johnson, J. "Persians as Centaurs in Xenophon's 'Cyropaedia", Transactions of the American Philological Association (1974-), 135, 177207.

Lendon 2006: Lendon, J.E., "Xenophon and the Alternative to Realist Foreign Policy: 'Cyropaedia' 3.1.14-31", The Journal of Hellenic Studies, 126, 82-98.

Létoublon y Montanari 2006: Létoublon, F., y S. Montanari "Le prince idéal de la Cyropédie ou l'histoire est un roman", A.A.V.V., Passions, vertus et vices dans l'ancien roman (Lyon, 2006).

Luccioni 1947: Luccioni, J., Les idées politiques et sociales de Xénophon (Paris, 1947).

Marchant 1970: Marchant, E.C., Xenophon. Opera Omnia, Vol. 4: Institutio Cyri (Oxford, 1970).

Mársico, Illarraga, Marzocca 2017: Mársico, C., Illarraga, R., y Marzocca, P. Jenofonte, La constitución de los lacedemonios, Hierón; PseudoJenofonte, La constitución de los atenienses (Buenos Aires, 2017)

Miller 1914: Miller, W., Xenophon. Cyropaedia. 2 Vols. (Harvard, 1914).

Nadon 2001: Nadon, C., Xenophon's Prince. Republic and Empire in the Cyropaedia (California, 2001).

Newell 1983: Newell, W.R., "Tyranny and the Science of Ruling in Xenophon's 'Education of Cyrus'", The Journal of Politics, 45, 889-906.

Prinz 1911: Prinz, W., De Xenophontis Cyri Institutione (Göttingen, 1911).

Reisert 2009: Reisert, J., “Ambition and Corruption in Xenophon's Education of Cyrus", Pólis, 26, 296-315.

Sandridge 2012: Sandridge, N., Loving Humanity, Learning, and Being Honored. The Foundations of Leadership in Xenophon's Education of Cyrus (Washington D.C., 2012).

Sano (en prensa): Sano, L., Xenophonte. Ciropedía (Sâo Paulo, en prensa).

Schaar 1919: Schaar, E., Xenophon's Staats-und Gesellschaftsideal und seine Zeit (Halle, 1919). 
Stadter 1991: Stadter, F., "Fictional Narrative in the Cyropaideia", American Journal of Philology, 112, 461-491.

Tamiolaki 2016: Tamiolaki, M.,"Emotion and Persuasion in Xenophon's Cyropaedia", Phoenix, 70, 40-61.

Tatum 1989: Tatum, J., Xenophon's Imperial Fiction. On the Education of Cyrus (Princeton, 1989).

Tuplin 2002: Tuplin, C. "Xenophon, Sparta and the Cyropaedia", Powell y Hodkinson (eds.), The Shadow of Sparta (London/New York, 2002).

Vegas Sansalvador 1987: Vegas Sansalvador, A., Jenofonte. Ciropedia (Madrid, 1987).

Wood 1964: Wood, N., “Xenophon’s Theory of Leadership”, C\&M, 25, 33-66. 
